\title{
The synthesis and structure of the strontium complex with anthranilic acid and triethanolamine
}

\begin{abstract}
In the framework of the systematic studies of the mixed-ligand complexes formation on the base of ethanolamines and aromatic carboxylic acids new strontium compound with triethanolamine and anthranilic acid has been synthesized. The structure of the obtained complex is determined by X-ray crystallography. In complex two triethanolamine molecules are tetradentantly coordinated by the central atom, while two molecules of anthranilic acid in the benzoate form are located in the outer sphere.

Keywords: strontium, triethanolamine, anthranilic acid, metal complex, X-ray structure analysis, H-bond
\end{abstract}

\author{
Volume 3 Issue 4 - 2018 \\ Ibragimov AB,' Ashurov JM,'2 Zakirov BS,' \\ Ibragimov BT, ${ }^{2}$ Alieva GK' \\ 'Institute of General and Inorganic Chemistry of AS, Uzbekistan \\ ${ }^{2}$ Institute of Bioorganic Chemistry of AS, Uzbekistan
}

\author{
Correspondence: Ibragimov AB, Institute of General and \\ Inorganic Chemistry of AS, M. Ulugbek Str, 77a, Tashkent, \\ I00 I25, Uzbekistan, Tel +998998872525, \\ Email aziz_ibragimov@mail.ru
}

Received: June 22, 2018 | Published: September 07, 2018

\section{Introduction}

It is well known that biological activity of pharmaceutical preparations may be significantly enhanced by metal complex formation ${ }^{1,2}$ which is especially crucial in case of substances with low activity. In this regard, we are carrying out a systematic study of the metal complex formation of aromatic carboxylic acids and ethanolamines demonstrating weak antimicrobial ${ }^{3}$ and growth stimulating effects. ${ }^{4}$ These substances were selected due to their low cost, availability and simplicity of the structure. Indeed, we have succeeded essentially increase a growth stimulating action through coordination complex formation of $\mathrm{Cu}$ with p-nitrobenzoic acid and monoethanolamine. ${ }^{5}$ Earlier we have synthesized coordination compounds of $\mathrm{Cu}$ and $\mathrm{Ni}$ with salicylic acid and triethanolamine. ${ }^{6}$ In these compounds, not all four donor groups of triethanolamine are involved to coordination because a transition metal atom tridentately coordinates two molecules of triethanolamine leaving one hydroxyl group unrelated. In order to place two tetradentantly coordinated molecules of triethanolamine around the metal atoms ions with a relatively large size such as alkali and alkaline earth metal ones are required. To obtain complexes of this type, we tested the synthesis in reaction media containing salts of target metals with a large ionic radius and potential ligands. In the case of synthesis with the participation of the $\operatorname{Sr}\left(\mathrm{NO}_{3}\right)_{2}$ salt, triethanolamine and salicylic acid a crystalline product containing single crystals suitable for X-ray diffraction analysis has been obtained. The structure determination of this compound attests that in it an inner coordination sphere of strontium ion contains two tetradentately coordinated triethanolamine molecules as anticipated. ${ }^{7}$ It is of a great interest to know what kind of the metal complex will be formed if to change salicylic acid to anthranilic one. This article is devoted to the synthesis and structure of such compound.

\section{Objects and methods of research}

To a solution of $0.105 \mathrm{~g}(0.5 \mathrm{mmol})$ of $\mathrm{Sr}\left(\mathrm{NO}_{3}\right)_{2}$ in $5 \mathrm{ml}$ of a waterethanol mixture ( $1: 1$ by volume) a hot ethanol solution of $0.138 \mathrm{~g}$ $(1 \mathrm{mmol})$ of anthranilic acid was added. $132 \mu \mathrm{l}$ of triethanolamine was added drop-wise to the resulting mixture with constant stirring. The reaction mixture was kept in an ultrasonic bath $(30 \mathrm{kHz})$ for 10 minutes.
The resulting solution was placed $\left(20^{\circ} \mathrm{C}\right)$ in a loosely-closed vial. After 14 days prismatic crystals are formed.

All reagents were readily available from commercial sources and were used as received without further purification. Analyses of $\mathrm{C}, \mathrm{H}$ and $\mathrm{N}$ were performed on a German Elementar Vario EL instrument. Data for the crystal structure determinations were collected at $293 \mathrm{~K}$ on an Oxford Diffraction Xcalibur-R CCD diffractometer (CuK $\alpha$ radiation, $\lambda=1.54184 \AA$, $\omega$-scan mode, graphite monochromator). Experimental data were collected using the CrysAlisPro program. ${ }^{8} \mathrm{An}$ absorption correction was applied by the multi-scan method using the same program. The structures were solved by a direct method of the SHELXS-97 program package ${ }^{9}$ and refined by full-matrix least squares using the SHELXL-97 program. ${ }^{10}$ All none hydrogen atoms were refined anisotropically. Hydrogen atoms were inserted at calculated positions and constrained with isotropic thermal parameters, except for the hydrogen atoms of some hydroxyl groups, which were located in a Fourier-difference map and refined isotropically. The molecular drawings were plotted by MERCURY program package. ${ }^{11,12}$ The crystallographic data and details of structure refinement of the compound are given in (Table 1).

Table I Basic crystallographic data and details of the structure refinement

\begin{tabular}{ll}
\hline Empirical formula & $\mathbf{C}_{\mathbf{1 2}} \mathbf{H}_{\mathbf{3 0}} \mathbf{N}_{\mathbf{2}} \mathbf{O}_{\mathbf{6}} \mathbf{S r}, \mathbf{2}\left(\mathbf{C}_{7} \mathbf{H}_{\mathbf{6}} \mathbf{N O}_{\mathbf{2}}\right)$ \\
\hline Formula weight & 658.25 \\
Crystal system & monoclinic \\
Space group & $\mathrm{P}_{1} / \mathrm{c}$ \\
$a, \AA$ & $10.4253(3)$ \\
$b, \AA$ & $23.0625(5)$ \\
$c, \AA$ & $12.7209(3)$ \\
$\beta$, deg & $103.668(3)$ \\
$V, \AA^{3}$ & $2971.92(13)$ \\
$\mathrm{Z}$ & 4 \\
$D_{\mathrm{x}}, \mathrm{gcm}^{-3}$ & 1.471 \\
\hline
\end{tabular}




\begin{tabular}{ll}
\hline Empirical formula & $\mathbf{C}_{12} \mathbf{H}_{30} \mathbf{N}_{2} \mathbf{O}_{6} \mathbf{S r}, \mathbf{2}\left(\mathbf{C}_{7} \mathbf{H}_{6} \mathbf{N O}_{2}\right)$ \\
\hline$\mu\left(\mathrm{Cu} K_{a}\right), \mathrm{mm}^{-1}$ & 3.041 \\
$T, \mathrm{~K}$ & 293 \\
Scan $\theta$ range, deg & $3.8,76.0$ \\
Range $h, k, l$ & $-9 / 12 ;-26 / 28 ;-15 / 14$ \\
Total data & 12679 \\
Independent data & 6038 \\
$R_{\text {int }}$ & 0.029 \\
Observed data $\left[F^{2} \geq 2 \sigma\right.$ & 5120 \\
$\left.\left(F^{2}\right)\right]$ & 1.04 \\
Goodness-of-fit $\left(F^{2}\right)$ & $0.0392,0.1057$ \\
$R_{1}, w R_{2}(I>2 \sigma(I))$ & $-0.35,0.89$ \\
$\Delta \rho_{\text {min/max }} e \AA^{-3}$ & \\
\hline
\end{tabular}

\section{Results and discussion}

The asymmetric part of the unit cell consists of 1 molecule of a complex cation and 2 molecules of anthranilic acid (Figure 1). The $\mathrm{Sr}^{+2}$ ion coordinates 2 molecules of triethanolamine through a nitrogen atom and three oxygen atoms, i.e. the maximum possible tetradentate method of coordination is realized due to the large ionic radius of the central atom. The coordinating polyhedron is a two-capped trigonal prism on the basis of which oxygen atoms are located while in the "cap" position nitrogen atoms of ligand molecules are positioned. The Sr-O bond lengths are in the range 2.542-2.606 $\AA$, the interatomic distances of Sr-N1 and Sr-N2 are 2.775 and $2.747 \AA$, respectively. An analysis of the 16 analogous bond lengths of Cambridge Structural Database $(\mathrm{CSD})^{13}$ indicates that the $\mathrm{Sr}-\mathrm{O} 24$ bond of $2.606 \AA$ by $0.054 \AA$

Table 2 Geometric parameters of intra- and intermolecular hydrogen bonds longer than the mean value. The remaining interatomic distances and valence angles have the usual values for analogous compounds.

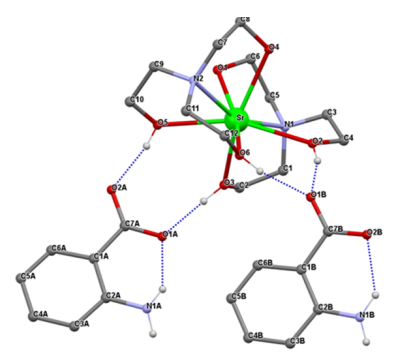

Figure I An asymmetric part of the unit cell of the crystal and atom numbering.

In result of the occupation of the inner coordination sphere of the central atom only by triethanolamine molecules the true mixedligand complex is not formed. Two molecules of anthranilic acid in a benzoate form are placed in the outer sphere in order to compensate the positive charge of the $\mathrm{Sr}$ ion. In other words, the supramolecular compound consisting of the cation in the form of complex ion with triethanolamine and anion of anthranilic acid in the benzoate form is crystallized from the solutions.

There is a strong intramolecular H-bond between the amino (donor) and carboxyl groups (acceptor) in molecules of anthranilic acid which is formed due to the adjacent arrangement of these groups. This bond is described by the graph-set $\mathrm{S}_{2}^{1}(6) .{ }^{14}$ There are 6 intermolecular H-bonds in the structure (Table 2) which combine structural units in cycles of different dimensions, for example, in rings with $\mathrm{R}_{4}^{4}(16)$-graph-sets. These cycles are associated in chains parallel to the direction [101] (Figure 2).

\begin{tabular}{|c|c|c|c|c|c|}
\hline \multirow{2}{*}{ Bond D-H-A } & \multicolumn{3}{|c|}{ Distance, A } & \multirow{2}{*}{$\begin{array}{l}\text { AngleD-H } \cdots \text { A, } \\
\text { deg }\end{array}$} & \multirow{2}{*}{$\begin{array}{l}\text { Coordinates of } \\
\text { atom } A\end{array}$} \\
\hline & D-H & 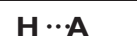 & $D \cdots A$ & & \\
\hline $\mathrm{OI}-\mathrm{HI} \cdots \mathrm{O} 2 \mathrm{~A}$ & $0.849(17)$ & $1.84 \mid(16)$ & $2.685(3)$ & 172(3) & $|-x|-y,, 2-z$ \\
\hline $\mathrm{O} 2-\mathrm{H} 2 \cdots \mathrm{OIB}$ & $0.84(3)$ & $1.92(3)$ & $2.73 I(3)$ & 162(3) & \\
\hline $\mathrm{O} 3-\mathrm{H} 3 \cdots \mathrm{OIA}$ & $0.85(4)$ & $1.80(4)$ & $2.642(4)$ & $175(5)$ & \\
\hline $\mathrm{O} 4-\mathrm{H} 4 \cdots \mathrm{O} 2 \mathrm{~B}$ & $0.84(3)$ & $1.86(3)$ & $2.677(4)$ & I64(4) & $-x,|-y|-z$, \\
\hline $\mathrm{O} 5-\mathrm{H} 5 \cdots \mathrm{O} 2 \mathrm{~A}$ & $0.84(2)$ & $1.87(2)$ & $2.693(3$ & $166(3)$ & \\
\hline $\mathrm{O} 6-\mathrm{H} 6 \cdots \mathrm{OIB}$ & $0.844(14)$ & $1.827(13)$ & $2.650(3)$ & 164(3) & \\
\hline NIB-HIBA $\cdots$ O $2 B$ & $0.87(3)$ & $1.97(4)$ & $2.666(5)$ & $137(4)$ & \\
\hline NIA-HIAA $\cdots$ OIA & $0.86(3)$ & $1.93(3)$ & $2.679(5)$ & $145(5)$ & \\
\hline
\end{tabular}

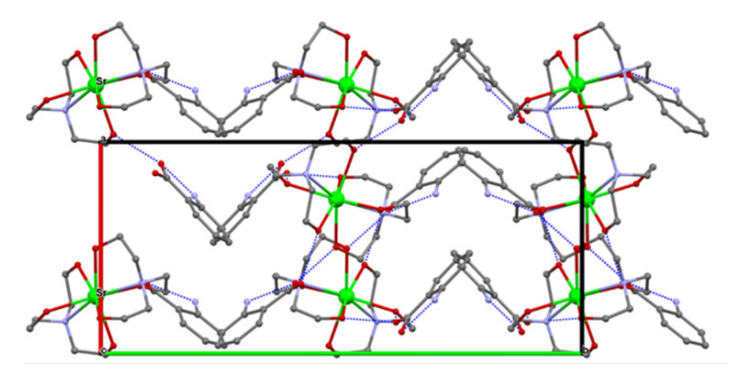

Figure 2 Crystal structure of the complex. 
There are 4 strontium complexes with ref-codes RUQSUR, AKEXET, GEGTOB and SUTZIQ in CSD in which the analogous tetradentant coordination of 2 molecules of triethanolamine takes place. However, in the outer sphere of these coordination compounds different counter-ion molecules are situated. The identical structure is also characteristic for complexes of other 7 metals, such as $\mathrm{Ca}, \mathrm{Pb}$, $\mathrm{Ba}, \mathrm{Cd}, \mathrm{Y}, \mathrm{Eu}$ and $\mathrm{Yb}$.

\section{Conclusion}

In result of the synthesis carried out in solutions containing $\mathrm{Sr}$ $\left(\mathrm{NO}_{3}\right)_{2}$, triethanolamine and anthranilic acid a new compound in the salt form is obtained. Inner coordination sphere of $\mathrm{Sr}$ is occupied only by triethanolamine molecules, displacing the second ligand, anthranilic acid, to the outer sphere. This type of structure of metal complexes with triethanolamine is typical for alkali and alkaline earth metals, i.e. for metals with a large ionic radius.

\section{Acknowledgements}

None.

\section{Conflict of interest}

The author declares that there is no conflict of interest.

\section{References}

1. Paul A, Thomas J, Johnson R, et al. Transition Metal Complexes of (z)4-((1H-indol-3-yl) methyleneamino) benzoic acid: Synthetic, Structural and Antibacterial studies. Chemical Science Review and Letters. 2015;4(13): 292-298

2. Devi J, Batra N. Synthesis, characterization and antimicrobial activities of mixed ligand transition metal complexes with isatin monohydrazone Schiff base ligands and heterocyclic nitrogen base. Spectrochim Acta A Mol Biomol Spectrosc. 2015;135:710-719.

3. Zardini HZ, Davarpanah M, Shanbedi M, et al. Microbial toxicity of ethanolamines Multiwalled carbon nanotubes. Biomed. Mater. Res. A. 2014;102(6):1774-1781.
4. Gaysin IA, Sagitova RN, Agliev KhM. The closest to the present invention is a composition for stimulating crop growth, comprising monoethanolamine, boric acid, copper vitriol and water. Patent of the Russian Federation; 1997, №2086126.

5. Ibragimov AB, Ashurov ZM, Ibragimov AB, et al. Synthesis, structure, and fungicidal activity of mono- and binuclear mixed-ligand copper complex with p-nitrobenzoic acid and monoethanolamine. Russian Journal of Coordination Chemistry. 2017;43(6):380-388.

6. Ibragimov AB, Zakirov BS, Ashurov ZM. Study of rheological properties of solaric acid solutions and precipitate pulp. Uzbekskiy himicheskiy jurnal. 2016;4:30-33.

7. Ibragimov AB, Ashurov ZM, AIbragimov AB, et al. Two supramolecular complexes based on 4-hydroxybenzoic acid and triethanolamine: Synthesis and structure. Russian Journal of Inorganic Chemistry. 2017;4(62):439-445.

8. Crys Alis Pro. X-ray structures of organic salts between diethanolamine and ortho- and para-isomers of aminobenzoic acid: A specific synthon responsible for an association of the components. UK: Oxford Diffraction; $2007.5 \mathrm{p}$

9. Sheldrick GM. Phase annealing in SHELX-90: direct methods for larger structures. Acta Crystallogr. 1990;A46:467-473.

10. Sheldrick GM. SHELXS97, SHELXL97, Programs for Crystal Structures Solution and Refinement. Germany: University of Göttingen; 1997. 250 p.

11. Macrae CF, Bruno IJ, Chisholm JA, et al. Mercury CSD 2.0-new features for the visualization and investigation of crystal structures. $J$ Appl Cryst. 2008;41(2):466-470.

12. Bernstein J, Davis RE, Shimoni L, et al. [2.2.2.2] Metacyclophane-1,9,17,25-tetrayne. Angew Chem Int. Ed. 1995;34:1555-1573.

13. The Cambridge Crystallographic Data Centre (CCDC); 2018.

14. Etter MC. Encoding and decoding hydrogen-bond patterns of organic compounds. Acc Chem Res. 1990;23(4):120. 